\title{
2000 CDC or 2007 WHO - What is the most sensitive anthropometric reference for determination of overweight and cardio-metabolic risk in children aged 6-10 years?
}

${ }^{1}$ Referral Center for the Treatment of Children and Adolescents, Campos dos Goytacazes, Rio de Janeiro, RJ, Brazil ${ }^{2}$ Faculty of Medicine of Campos dos Goytacazes (FMC), Rio de Janeiro, Brazil ${ }^{3}$ Department of Maternal and Child Health, School of Public Health, University of São Paulo (FSP-USP), São Paulo, SP, Brazi ${ }^{4}$ Pediatric Endocrinology Unit, Instituto da Criança University of São Paulo Medical School (FMUSP), São Paulo, SP, Brazil

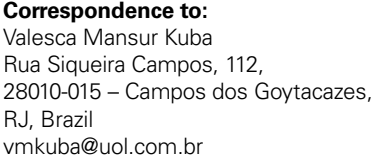

Received on Sept/25/2014 Accepted on Mar/10/2015
Valesca Mansur Kuba ${ }^{1,2}$, Claudio Leone 3 , Durval Damiani ${ }^{4}$

\begin{abstract}
Objective: To compare the two anthropometric standards for screening of overweight and cardiometabolic risk in 6-10-year-old children. Subjects and methods: This cross-sectional study included 175 subjects attending the Referral Center for the Treatment of Children and Adolescents in Campos, Rio de Janeiro. They were classified according to CDC and WHO BMI z scores as normal-weight ( $z$ score $>-1$ and $<1$ ), overweight $(z$-score $\geq 1$ and $<2$ ) or obese $(z$-score $\geq 2)$. Sensitivities and specificities in predicting systolic (SBP), diastolic (DBP) blood pressure and homeostatic model assessment insulin resistance index (HOMA-IR) alterations were calculated. Results: There was a major difference in 11 children who rated overweight by the CDC but were reclassified as obese by the WHO. Their mean z-scores for SBP $(1.71 \pm 1.54)$, DBP $(2.64 \pm 1.83)$ and HOMA-IR $(1.84 \pm 0.98)$ were higher than those classified as overweight by both references $(\mathrm{SBP}=0.49 \pm 1.34, \mathrm{p}<0.023, \mathrm{DBP}=1.45 \pm 0.97, \mathrm{p}<$ 0.04 and HOMA $=1.24 \pm 0.67, \mathrm{p}<0.04)$, but were similar to those classified as obese by both criteria $(\mathrm{SBP}=1.25 \pm 2.04, \mathrm{p}=0.60, \mathrm{DBP}=1.94 \pm 1.19, \mathrm{p}=0.50$ and HOMA $=2.09 \pm 1.12, \mathrm{p}=0.76)$. Conclusion: the $2007 \mathrm{WHO}$ reference was the most sensitive in screening for overweight and alterations in blood pressure and HOMA-IR in 6-10-year-old children. Arch Endocrinol Metab. 2015;59(3):220-5
\end{abstract}

Keywords

Cardio-metabolic risk; obesity; children; Centers for Disease Control and Prevention; World Health Organization

\section{INTRODUCTION}

$I^{\prime}$ $\mathrm{n}$ the last few decades, more affluent lifestyles have resulted in a worldwide increase in the prevalence of childhood obesity, which is considered a health problem of epidemic proportions (1). In the United States, the most recent data from the Centers for Disease Control and Prevention (CDC) National Health and Nutrition Examination Survey (NHANES) reported that the prevalence of obesity in children aged under 5 years and 6-11 years had increased from $5 \%$ and $4 \%$, respectively, in 1971 to $12 \%$ and $17 \%$, respectively, in 2006 (2). In Brazil, almost $33.5 \%$ of $5-9$ year-olds are overweight, with the highest prevalence in southeast Brazil (3).

Childhood obesity is an important risk factor for the development of coronary heart disease (4), and a marked increase in body mass index (BMI) after 10 years of age has been considered the strongest predictor of pre- mature death resulting from a heart attack in adulthood (5). Insulin resistance also has an important role in the pathogenesis of metabolic syndrome and can lead to type 2 diabetes and poor outcomes (5).

In 2000, the CDC reviewed the NHANES growth charts and corrected some of their shortcomings (6). However, because of the increase in childhood obesity, the World Health Organization (WHO) more recently reconstructed the 2000 CDC BMI reference measurements and smoothed their skewness to increase their sensitivity in diagnosing overweight and thus provide an adequate transition from standard curves for the under-fives to the reference curves for older children $(7,8)$.

The study aimed to compare the CDC and WHO BMI reference criteria for screening of overweight and cardio-metabolic risk in 6-10-year-old children, using the same critical cut-off points. 


\section{SUBJECTS AND METHODS}

This was a cross-sectional study of a sequential sample of children attending the Pediatric Endocrinology outpatient clinic of the Referral Center for the Treatment of Children and Adolescents (CRTCA) in Campos, State of Rio de Janeiro, in the southeast of Brazil. Data were collected between November 2006 and April 2008. The sample comprised 175 children aged 6-10 years, of both sexes, at the Tanner I pubertal stage. Most participants were from low-income families and many were of African descent. The children were referred to the CRTCA by pediatricians $(60 \%)$ or by the principals of public schools in Campos $(40 \%)$. The reason for sending children who were slim was to check whether their weight or height was normal. Overweight/obese children were also sent for this reason, or because dyslipidemia had been found on initial screening by a pediatrician. Children with thyroid, kidney or liver disorders, psychiatric diseases, non-essential hypertension or acute or chronic infections, who were using any medication that could interfere with the variables analyzed, or who were undergoing treatment for weight control were excluded.

The study was performed according to the Helsinki Declaration and approved by the Ethical Committee in Research of the University of São Paulo (203/2011). Subjects participated in the study only after the Terms of Consent were read and had been signed by their parents or guardians. All data were anonymized for the analysis.

All subjects were examined by the same observer, who evaluated body weight (measured to the nearest $0.1 \mathrm{~kg}$ on a Filizola adult-type scale with the subject wearing light clothes, without shoes and with their feet juxtaposed) and height (measured to the nearest 0.1 $\mathrm{cm}$ on a wall-mounted stadiometer of Halpender-Holtain type [Tonelli]) (9).

Systolic blood pressure (SBP) and diastolic blood pressure $(\mathrm{DBP})$ were measured $(\mathrm{mmHg})$ in the right upper arm, with a cuff appropriate to the length and circumference of the arm, after the child was at rest and had been sitting down for at least 5 minutes. BP was checked twice during the appointment and the mean of the two measurements was used for analysis. Values over the $90^{\text {th }}$ percentile were considered abnormal (10). $\mathrm{BP} z$-scores were also calculated based on the reference values for sex, age and height (11). BP was checked again at the second appointment, about 45 days after the first evaluation, when the children returned and results of complementary tests were evaluated.

The children were classified according to the CDC criteria as normal weight $\left(\mathrm{BMI}>5^{\text {th }}\right.$ and $<85^{\text {th }}$ percentiles) or overweight (BMI $\geq 85^{\text {th }}$ percentile). BMI $\mathrm{z}$-scores were then calculated from the 2000 CDC and 2007 WHO data, which classified them as normal weight (BMI z-score $>-1$ and $<1$ ), overweight $($ BMI $z$-score $\geq 1$ and $<2$ ) or obese (BMI $z$-score $\geq 2$ ). Then, the 2000 CDC standards and 2007 WHO BMI z scores were compared in relation to their sensitivity in diagnosing overweight, obesity and cardio-metabolic risk.

\section{Laboratory evaluation}

At the first clinical evaluation, the parents or guardians of all children were instructed on the collection of blood samples after a 12-hour overnight fast for the measurement of fasting glucose, total cholesterol (TC), low-density lipoprotein (LDLc), triglycerides (TG), high-density lipoprotein (HDLc), and insulin. LDLc was determined using Friedewald's formula (12). Lipid levels were evaluated according to the $1^{\text {st }}$ Brazilian Guidelines on the prevention of atherosclerosis in childhood and adolescence, which consider normal levels $\mathrm{TC}<150 \mathrm{mg} / \mathrm{dL}, \mathrm{LDL}<100 \mathrm{mg} / \mathrm{dL}, \mathrm{TG}<$ $100 \mathrm{mg} / \mathrm{dL}$ and HDL $\geq 45 \mathrm{mg} / \mathrm{dL}$ (13). Homeostatic Model Assessment-Insulin Resistance (HOMAIR) was calculated (14) and the cut-off value $\geq 2.5$ was chosen, based on the study of Madeira and cols. (15) in a cohort of the same age from Rio de Janeiro. Glucose and lipid profiles were determined by a colorimetric enzymatic method, using a Hitachi-Roche modular system (Roche Diagnostics GmbH, Mannheim, Germany). Insulin was measured by a chemiluminescence kit (Bayer, Germany).

\section{Statistical analysis}

$\mathrm{BP}$ values and metabolic parameters were compared among groups using the Student $t$-test for continuous variables with a normal distribution and the MannWhitney $U$ test for variables without a normal distribution. BMI $z$-scores were calculated according to the 2007 WHO reference values using AnthroPlus software. The sensitivity and specificity of estimated 2007 BMI $z$-scores for detecting changes in BP or HOMAIR were calculated by receiver operating characteristic (ROC) curve analysis. McNemar's test was used to compare CDC and WHO BMI z-scores, considering 
$\mathrm{p}<0.05$ as significant, with a confidence interval of 95\%. Insulin and HOMA-IR values were not normally distributed on the Kolmogorov-Smirnof test and thus it was necessary to transform them into logarithmic values. Medcalc version 12.1.0.0 (Mariakerke, Blegium), GraphPad Instat version 3.00 and Graph Pad Prism 5 version 5.04 (San Diego, CA, USA) were used for statistical analysis.

\section{RESULTS}

A total of 175 children were included in the study, with 88 classified as normal-weight and 87 as overweight/ obese. The mean age \pm standard deviation of the two groups was $8.08 \pm 1.24$ years and $8.28 \pm 1.15$ years, respectively. There were 40 girls and 48 boys in the normal-weight group, and 37 girls and 50 boys in the overweight/obese group. In the normal-weight group 47\% were white and 53\% were African American; in the overweight/obese group, $49 \%$ were white and $51 \%$ were African American. The demographic and clinical data of the children are shown in table 1 . There was a significant correlation between BP values recorded at the first and second appointments $(r=0.95$ and $r=$ 0.91 for SBP and DBP, respectively).

Table 1. Demographic and clinical data of normal-weight and overweight/ obese 6-10-year-old children from Campos, Brazil

\begin{tabular}{lccc}
\hline Group & $\begin{array}{c}\text { Normal- } \\
\text { weight } \\
\mathbf{n = 8 8}\end{array}$ & $\begin{array}{c}\text { Overweight/ } \\
\text { obese } \\
\mathbf{n = 8 7}\end{array}$ & p-value \\
\hline Girls & $40(45 \%)$ & $37(43 \%)$ & $p=0.8122$ \\
White & $41(47 \%)$ & $43(49 \%)$ & $p=0.7630$ \\
Age (mean \pm SD) & $8.08 \pm 1.24$ & $8.28 \pm 1.15$ & $p=0.2703$ \\
Height/age z score & $-0.31 \pm 1.08$ & $0.84 \pm 1.17$ & $p<0.0001$ \\
BMl z-score (mean \pm SD) & $-0,16 \pm 0.64$ & $2.90 \pm 0.13$ & $p<0.0001$ \\
SBP z-score (mean $\pm S D)$ & $-0.91 \pm 1.12$ & $0.94 \pm 0.16$ & $p<0.0001$ \\
DBP z-score (mean $\pm S D)$ & $0.32 \pm 0.85$ & $1.71 \pm 1.15$ & $p<0.0001$ \\
\hline
\end{tabular}

BMl: body mass index; DBP: diastolic BP; SBP: systolic blood pressure.
The 2000 CDC and 2007 WHO reference values were concordant in classifying 121 children $(69 \%)$, with 88 classified as normal-weight, 24 as overweight and nine as obese. However, the reference values showed a discrepancy in 54 children (31\%). Of these, three classified as normal-weight according to CDC guidelines were classified as overweight by WHO criteria, and 11 classified as overweight by CDC guidelines were classified as obese by WHO criteria. The remaining 40 children were determined to be obese in both sets of criteria, but, according to CDC criteria they were classified between 2 and 3 BMI z-scores (mean 2.85) compared with BMI z-scores higher than 3 (mean, 6.72) when classified by WHO criteria. The WHO reference values classified $2.29 \%$ more children in the BMI z-score range between $\mathrm{l}$ and $2(3 / 175$, $\mathrm{p}=0.125)$, and $6.29 \%$ more children in the BMI z-score range between 2 and $3(11 / 175, \mathrm{p}<0.001)$.

Table 2 shows the means of BP $z$-scores and HOMA-IR of the children reclassified as obese by the WHO Chart ( $\mathrm{n}$ $=11$ ), in comparison with those whose classification was concordant in the two systems. The mean SBP z-scores of the reclassified children were significantly higher than those of children classified as overweight according to both reference criteria $(n=24)$. The same was observed in relation to the means of DBP $\mathrm{z}$-scores and HOMA-IR. There were no differences between means of fasting glucose, HDL, TG and LDL between these groups. On the other hand, the means of BP z-scores and HOMA-IR of the 11 reclassified children were similar to those in children classified as obese in both systems $(n=9)$, as were the means of glucose, HDL, TG and LDL.

As shown in Tables 3, 4 and 5 there were differences in BMI $z$-score sensitivity and specificity according to CDC and WHO criteria. Specifically, for a BMI z-score $\geq$ 2 , the sensitivities of the WHO criteria were higher than the CDC criteria for predicting alterations in SBP, DBP and HOMA-IR $(69.7 \%, 61.8 \%$ and $74.4 \%$, respectively, compared with $48.5 \%, 47.2 \%$ and $67.4 \%$, respectively).

Table 2. Comparison of the means of BP z-scores and HOMA-IR of the children reclassified as obese according to WHO standards with those whose classification was concordant

\begin{tabular}{|c|c|c|c|c|}
\hline Groups & $\begin{array}{l}\text { Reclassified children } \\
\quad(n=11)\end{array}$ & $\begin{array}{l}\text { Normal-weight } \\
\quad(\mathrm{n}=\mathbf{8 8})\end{array}$ & $\begin{array}{l}\text { Overweight } \\
(n=24)\end{array}$ & $\begin{array}{l}\text { Obese } \\
(\mathrm{n}=9)\end{array}$ \\
\hline SBP z-score & $1.71 \pm 1.54$ & $\begin{array}{l}-0.91 \pm 1.12 \\
(p<0.0002)\end{array}$ & $\begin{array}{c}0.49 \pm 1.34 \\
(p<0.023)\end{array}$ & $\begin{array}{c}1.25 \pm 2.04 \\
(p=0.60)\end{array}$ \\
\hline DBP z-score & $2.64 \pm 1.83$ & $\begin{array}{c}0.32 \pm 0.85 \\
(p<0.02)\end{array}$ & $\begin{array}{c}1.45 \pm 0.97 \\
(p<0.04)\end{array}$ & $\begin{array}{c}1.94 \pm 1.19 \\
(p=0.50)\end{array}$ \\
\hline HOMA-IR & $1.84 \pm 0.98$ & $\begin{array}{c}0.95 \pm 0.58 \\
(p<0.007)\end{array}$ & $\begin{array}{c}1.24 \pm 0.67 \\
(p<0.04)\end{array}$ & $\begin{array}{c}2.09 \pm 1.12 \\
(p=0.76)\end{array}$ \\
\hline
\end{tabular}

HOMA-IR: Homeostatic Model Assessment-Insulin Resistance; DBP: diastolic BP; SBP: systolic blood pressure. 
Table 3. Sensitivity and specificity of BMl z-scores as the adopted reference in predicting SBP alteration in 175 normal-weight and overweight in 6-10-year-old children from Campos

\begin{tabular}{|c|c|c|c|c|c|c|}
\hline & \multicolumn{6}{|c|}{ BMI z-score } \\
\hline & \multicolumn{3}{|c|}{$z \geq 1$} & \multicolumn{3}{|c|}{$z \geq 2$} \\
\hline & WHO & CDC & p & WHO & CDC & $\mathbf{P}$ \\
\hline Sensitivity & $\begin{array}{c}90.9 \% \\
*(75.7-98.1)\end{array}$ & $\begin{array}{c}90.9 \% \\
(75.7-98.1)\end{array}$ & ns & $\begin{array}{c}69.7 \% \\
(51.3-84.4)\end{array}$ & $\begin{array}{c}48.5 \% \\
(30.8-66.5)\end{array}$ & $<0.0001$ \\
\hline Specificity & $\begin{array}{c}60.6 \% \\
*(52.0-68.7)\end{array}$ & $\begin{array}{c}62.7 \% \\
(54.2-70.6)\end{array}$ & ns & $\begin{array}{c}74.6 \% \\
(66.7-81.6)\end{array}$ & $\begin{array}{c}77.5 \% \\
(69.7-84.0)\end{array}$ & $<0.03$ \\
\hline
\end{tabular}

* \% (95\% confidence interval).

CDC: Centers for Disease Control and Prevention BMI criteria; WHO: World Health Organization BMI criteria; ns: not significant.

Table 4. Sensitivity and specificity of BMI z-scores as the adopted reference in predicting DBP alteration in 175 normal-weight and overweight 6-10-yearold children from Campos

\begin{tabular}{|c|c|c|c|c|c|c|}
\hline & \multicolumn{6}{|c|}{ BMI z-score } \\
\hline & \multicolumn{3}{|c|}{$z \geq 1$} & \multicolumn{3}{|c|}{$z \geq 2$} \\
\hline & WHO & CDC & $\mathbf{p}$ & WHO & CDC & $\mathbf{p}$ \\
\hline Sensitivity & $\begin{array}{c}85.5 \% \\
*(73,3-93,5)\end{array}$ & $\begin{array}{c}83.6 \% \\
(71,2-92,2)\end{array}$ & ns & $\begin{array}{c}61.8 \% \\
(47,7-74,6)\end{array}$ & $\begin{array}{c}47.2 \% \\
(33,7-61,3 \%)\end{array}$ & $<0.0001$ \\
\hline Specificity & $\begin{array}{c}67.5 \% \\
*(58.3-75.8)\end{array}$ & $\begin{array}{c}64.4 \% \\
(55.6-70.6)\end{array}$ & ns & $\begin{array}{c}79.2 \% \\
(70.8-81,0)\end{array}$ & $\begin{array}{c}85.6 \% \\
(78.4-91.1)\end{array}$ & $<0.0005$ \\
\hline
\end{tabular}

* $\%(95 \%$ confidence interval).

CDC: Centers for Disease Control and Prevention BMI criteria; WHO: World Health Organization BMI criteria; ns: not significant.

Table 5. Sensitivity and specificity of BMl z-scores as the adopted reference in predicting HOMA-IR alterations in 175 normal-weight and overweight 6-10-year-old children from Campos

\begin{tabular}{|c|c|c|c|c|c|c|}
\hline & \multicolumn{6}{|c|}{ BMI z- score z } \\
\hline & \multicolumn{3}{|c|}{$z \geq 1$} & \multicolumn{3}{|c|}{$z \geq 2$} \\
\hline & WHO & CDC & $\mathbf{p}$ & WHO & CDC & $\mathbf{p}$ \\
\hline Sensitivity & $\begin{array}{c}83.7 \% \\
\star(69.3-93.2)\end{array}$ & $\begin{array}{c}83.7 \% \\
(69.3-93.2)\end{array}$ & ns & $\begin{array}{c}74.4 \% \\
(58.8-86.5)\end{array}$ & $\begin{array}{c}67.4 \% \\
(51.5-80.9)\end{array}$ & $<0.001$ \\
\hline Specificity & $\begin{array}{c}62.1 \% \\
*(53.3-70.4)\end{array}$ & $\begin{array}{c}69.2 \% \\
(60.1-77.3)\end{array}$ & 0.0002 & $\begin{array}{c}79.5 \% \\
(71.7-86.1)\end{array}$ & $\begin{array}{c}85.6 \% \\
(78.4-91.1)\end{array}$ & $<0.001$ \\
\hline
\end{tabular}

* \% (95\% confidence interval).

CDC: Centers for Disease Control and Prevention BMI criteria; WHO: World Health Organization BMI criteria; ns: not significant.

\section{DISCUSSION}

Anthropometric reference values for children represent normal growth and constitute a valuable tool in evaluating nutritional status and child health (16). In 2000 , the CDC published growth charts using data from NHANES III studies (6), and also presented BMI reference values according to sex and age (17), which have largely been used until recently. One of the limitations of these standards was the skewness at upper levels (BMI $\geq 85^{\text {th }}$ centile), leading to underestimation of overweight (8). Thus, in view of the global epidemic of obesity, after publishing new 2006 reference stan- dards for the under-fives, the WHO also developed reference standards in 2007 for 5-19 year-old children, based on data from 2000 CDC data. As a consequence of smoothing their skewness, lower BMI vales corresponded to the BMI z-scores, which increased the sensitivity for screening of overweight and obesity (8).

Most of the studies comparing CDC and WHO reference values for determination of nutritional status were conducted in the under-fives. Our study is original because it not only compared the standards in the diagnosis of overweight in older children, but also the metabolic risk. In our sample, the WHO criteria cate- 
gorized 11 more children as obese $(6.29 \%)$ than the CDC criteria, and showed a greater sensitivity for this purpose. Our results were similar to those of Leone and cols. (18), who compared both standards and noted an increase in obesity prevalence in 3-7-year-old children from Santo André, São Paulo, using the WHO reference values, which showed an increased sensitivity in spite of a lower specificity. From an epidemiologic perspective, the nutritional transition observed worldwide may partially explain the higher obesity prevalence in subjects studied by Leone and cols., with a tendency to overweight in younger children, even as early as pre-school. In the current study, the WHO reference standard was also more sensitive not only in diagnosing obesity, but also its severity, because there were a number of children with a BMI z-score higher than 4 who were classified with a mean BMI z-score of only 2.85 according to the CDC criteria.

Another important issue is the evaluation of cardiometabolic risk. It is necessary to consider the implications of changing BMI cut-off values for screening obesity (19). The children who were reclassified from overweight to obese by WHO criteria, were also found to have a metabolic profile similar to obese children. Thus, the WHO criteria were sensitive for prediction of high BP and insulin resistance, without loss of specificity, when the BMI z-score cut-off increased from 1 to 2 , while there was a reduction in sensitivity using the CDC criteria. Our results contrast with those of Kakinami and cols. (20), who, in spite of observing an increase in obesity prevalence using WHO reference values, did not find any difference in sensitivity between the CDC and WHO criteria for determining cardio-metabolic risk. However, their sample constituted teenagers from Quebec, whose body composition could be different from our subjects who were mainly pre-pubertal and approximately half were non-white. African Americans and Latin Americans generally have higher prevalence and severity of hypertension (21). Thus, the choice of the cut-off depends on the aim of the study: for screening metabolic risk, variables other than BMI are required (such as HOMA-IR, lipid levels and BP), and it is preferable to use the more sensitive chart. This would allow clinicians to determine the risk of cardiovascular disease and type 2 diabetes as early as possible (22).

We would like to highlight some limitations of our study. The first was that we did not have access to data on other factors that could influence BP, such as family history of hypertension and the eating habits of the population under study. The second limitation was related to the use of the HOMA-IR for diagnosing IR. Use of the gold standard, the euglycemic hyperinsulinemic clamp, is not feasible in children, because it is a complex procedure, difficult to perform and expensive. As an alternative, the HOMA-IR, which requires only fasting glucose and insulin measurements, is used $(23,24)$. Some authors argue that there is no consensus regarding the ideal HOMA-IR cut-off value in children, and commercially available kits also measure pro-insulin levels (25). However, the HOMA-IR is reliable and practical, since it is standardized for a specific population as we chose, based on that of the study of Madeira and cols., whose data came from a cohort of children of similar age to ours and originating from Rio de Janeiro (15). Furthermore, results of HOMA-IR are strongly correlated with those obtained using the euglycemic hyperinsulinemic clamp $(r=0.82)$ and are thus considered reliable for epidemiologic studies on a large scale $(26,27)$. Regarding the kits used to measure insulin, cross-reactivity with pro-insulin is small (an estimated $8 \%$ for the chemiluminescence test). We would like to emphasize that, because our sample comprised a significant proportion of African American descent, was drawn from low-income families and public schools in the north of Rio de Janeiro, we suggest caution in the extrapolation of our results.

In conclusion, our study indicated that $2007 \mathrm{WHO}$ reference standards were more sensitive than the 2000 CDC criteria not only for screening for overweight and obesity, but also for predicting alterations in BP and HOMA-IR in 6-10-year-old children. Other multicenter studies are necessary, including subjects of different ethnic groups, ages and socioeconomic status, since prevention of cardiovascular diseases and diabetes begins by early screening for overweight through an accurate anthropometric evaluation.

Author contributions: Valesca Mansur Kuba was responsible for the conception, design, drafting and interpretation of the results. Claudio Leone and Durval Damiani were responsible for the analysis of data, interpretation of the results, revision and final approval of the version to be published.

Acknowledgements: We thank Dr José Tarcísio Thichiebaut, who helped us to interpret our results. We also thank Dr Cláudio Manoel Petrucci who allowed the assays to be run in the Municipal Hospital of Guarus.

Disclosure: no potential conflict of interest relevant to this article was reported. 


\section{REFERENCES}

1. Lobstein TJ, James WP, ColeTJ. Increasing levels of excess weight among children in England. Int $\mathrm{J}$ Obes Relat Metab Disord. 2003;27(9):1136-8.

2. Centers for Disease Control and Prevention. Overweight and Obesity. Childhood Obesity Facts - Prevalence of Childhood Obesity in the United States, 2011-2012. Available at: <www.cdc.gov/ obesity/childhood/prevalence.html>

3. Estudo Nacional de Despesa Familiar (ENDEF), 1989. Pesquisa Nacional sobre saúde e nutrição (PNSN), 2002-03. Pesquisa sobre Orçamentos Familiares (POF) - IBGE, 2008-2009. Available at: $<w w w . i b g e . g o v . b r>$.

4. Bell LM, Byrne S, Thompson A, Ratnam N, Blair E, Bulsara M, et al. Increasing body mass index z-score is continuously associated with complications of overweight in children, even in the healthy weight range. J Clin Endocrinol Metab. 2007;92(2):517-22.

5. Baker JL, Olsen LW, Sørensen TIA. Childhood body mass index and the risk of coronary heart disease in adulthood. N Engl Med J. 2007;357:2329-37.

6. Ogden CL, Kuczmarski RJ, Flegal KM, Mei Z, Guo S, Wei R, et al. Centers for Disease Control and Prevention 2000 growth charts for the United States: improvements to the 1977 National Center for Health Statistics version. Pediatrics. 2002;109(1):45-60.

7. de Onis M, Onyango AW, Borghi E, Garza C, Yang H. Comparison of the World Health Organization (WHO) Child Growth Standards and the National Center for Health Statistics/WHO international growth reference: implications for child health programmes. Public Health Nutr. 2006;9:942-7.

8. de Onis M, Onyango AW, Borghi E, Siyam A, Nishida C, Siekmann J. Development of a WHO growth reference for school-aged children and adolescents. Bull World Health Organ. 2007;85(9):660-7.

9. National Health Statistics Examination Survey. Anthropometry procedures manual. Available at: <http://www.cdc.gov/nchs/data/ nhanes/bm.pdf.2002>.

10. Falkner B, Gidding SS, Portman R, Rosner B. Blood pressure variability and classification of prehypertension and hypertension in adolescence. Pediatrics. 2008;122(2);238-42.

11. National High Blood Pressure Education Program Working Group on High Blood Pressure in Children and Adolescents. The fourth report on the diagnosis, evaluation, and treatment of high blood pressure in children and adolescents. Pediatrics. 2004;114(2 Suppl 4th Report):555-76.

12. Friedewald WT, Levy RI, Fredrickson DS. Estimation of the concentration of low-density lipoprotein cholesterol in plasma, without use of the preparative ultracentrifuge. Clin Chem. 1972;18(6):499502.

13. Back Giuliano Ide C, Caramelli B, Pellanda L, Duncan B, Mattos S, Fonseca $\mathrm{FH}$; Sociedade Brasileira de Cardiologia. [I guidelines of prevention of atherosclerosis in childhood and adolescence]. Arq Bras Cardiol. 2005;85 Suppl 6:4-36.
14. Matthews DR, Hosker JP, Rudenski AS, Naylor BA, Treacher DF, Turner RC. Homeostasis model assessment: insulin resistance and beta-cell function from fasting plasma glucose and insulin concentrations in man. Diabetologia. 1985;28(7):412-9.

15. Madeira IR, Carvalho CN, Gazolla FM, de Matos HJ, Borges MA, Bordallo MA. Ponto de corte do Índice Homeostatic Model Assessment for Insulin Resistance (HOMA-IR) avaliado pela curva Receiver Operating Characteristic (ROC) na detecção de síndrome metabólica em crianças pré-púberes com excesso de peso. Arq Bras Endocrinol Metab. 2008;52(9):1466-73.

16. Garza $C$, de Onis M. Rationale for developing a new international reference. Food Nutr Bull. 2004;25(1 Suppl):S5-14.

17. Centers for Disease Control and Prevention and National Center for Health Statistics. Growth charts revision update [online] Hyaltsville: 2002 [cited 2002 May 11]. Available at: <http://www.cdc. gov/nchs/about/major/nhanes/gcrevision.htm>.

18. Leone C, Bertoli CJ, Schoeps DO. Novas curvas de crescimento da Organização Mundial da Saúde: comparação com valores de crescimento de crianças pré-escolares das cidades de Taubaté e Santo André, São Paulo. Rev Paul Pediatr. 2009;27(1):40-7.

19. Kopelman PG. Obesity as a medical problem. Nature. 2000;404(6778):635-43.

20. Kakinami L, Henderson M, Delvin EE, Levy E, O'Loughlin J, Lambert M, Paradis G. Association between different growth curve definitions of overweight and obesity and cardiometabolic risk in children. CMAJ. 2012;184(10):E539-50.

21. McCarthy HD, Yancey AK, Siegel JM, Wong WK, Ward A, Leslie J, et al. Correlation of obesity with elevated blood pressure among racial/ethnic minority children in two Los Angeles middle schools. Prev Chronic Dis. 2008;5(2):A46.

22. Lyon CJ, Law RE, Hsue L, HsueWA. Minireview: adiposity, inflammation, and atherogenesis. Endocrinology. 2003;144(6):2195-200.

23. Bonora $E$, Targher G, Alberiche M, Bonadonna RC, Saggiani F, Zenere MB, et al. Homeostasis model assessment closely mirrors the glucose clamp technique in the assessment of insulin sensitivity: studies in subjects with various degrees of glucose tolerance and insulin sensitivity. Diabetes Care. 2000;23(1):57-63.

24. Gungor N, Saad R, Janosky J, Arslanian S. Validation of surrogate estimates of insulin sensitivity and insulin secretion in children and adolescents. J Pediatr. 2004;144(1):47-55.

25. Levy-Marchal C, Arslanian S, Cutfield W, Sinaiko A, Druet C, Marcovecchio $\mathrm{ML}$, et al. Insulin resistance in children: consensus, perspective, and future directions. J Clin Endocrinol Metab. 2010;95(12):5189-98.

26. Ferreira AP, Oliveira CE, França NM. Metabolic syndrome and risk factors for cardiovascular disease in obese children: the relationship with insulin resistance (HOMA-IR). J Pediatr (Rio J). 2007;83(1):21-6.

27. Tresaco B, Bueno G, Pineda I, Moreno LA, Garagorri JM, Bueno M. Homeostatic model assessment (HOMA) index cut-off values to identify the metabolic syndrome in children. J Physiol Biochem. 2005;61(2):381-8. 